\title{
Front Matter: Volume 9679
}

, "Front Matter: Volume 9679," Proc. SPIE 9679, AOPC 2015: Optical Fiber Sensors and Applications, 967901 (15 October 2015); doi:

10.1117/12.2222195

SPIE. Event: Applied Optics and Photonics China (AOPC2015), 2015, Beijing, China 




\title{
AOPC 2015: Optical Fiber Sensors and Applications
}

\author{
Yanbiao Liao \\ Weixu Zhang \\ Desheng Jiang \\ Wei Wang \\ Gilberto Brambilla \\ Editors
}

5-7 May 2015

Beijing, China

Organized by

Chinese Society for Optical Engineering (China)

Photoelectronic Technology Committee, Chinese Society of Astronautics (China)

Science and Technology on Low-light-level Night Vision Laboratory (China)

Sponsored by

Chinese Society for Optical Engineering (China)

Technical Co-sponsor and Publisher

SPIE

Volume 9679 
The papers in this volume were part of the technical conference cited on the cover and title page. Papers were selected and subject to review by the editors and conference program committee. Some conference presentations may not be available for publication. Additional papers and presentation recordings may be available online in the SPIE Digital Library at SPIEDigitallibrary.org.

The papers reflect the work and thoughts of the authors and are published herein as submitted. The publisher is not responsible for the validity of the information or for any outcomes resulting from reliance thereon.

Please use the following format to cite material from these proceedings:

Author(s), "Title of Paper," in AOPC 2015: Optical Fiber Sensors and Applications, edited by Yanbiao Liao, Weixu Zhang, Desheng Jiang, Wei Wang, Gilberto Brambilla, Proceedings of SPIE Vol. 9679 (SPIE, Bellingham, WA, 2015) Six-digit Article CID Number.

ISSN: 0277-786X

ISSN: 1996-756X (electronic)

ISBN: 9781628419047

Published by

SPIE

P.O. Box 10, Bellingham, Washington 98227-0010 USA

Telephone +1 3606763290 (Pacific Time) · Fax + 13606471445

SPIE.org

Copyright @ 2015 , Society of Photo-Optical Instrumentation Engineers.

Copying of material in this book for internal or personal use, or for the internal or personal use of specific clients, beyond the fair use provisions granted by the U.S. Copyright Law is authorized by SPIE subject to payment of copying fees. The Transactional Reporting Service base fee for this volume is $\$ 18.00$ per article (or portion thereof), which should be paid directly to the Copyright Clearance Center (CCC), 222 Rosewood Drive, Danvers, MA 01923. Payment may also be made electronically through CCC Online at copyright.com. Other copying for republication, resale, advertising or promotion, or any form of systematic or multiple reproduction of any material in this book is prohibited except with permission in writing from the publisher. The CCC fee code is 0277-786X/15/\$18.00.

Printed in the United States of America.

Publication of record for individual papers is online in the SPIE Digital Library.

\section{SPIE. DIGITAL}

Paper Numbering: Proceedings of SPIE follow an e-First publication model. A unique citation identifier (CID) number is assigned to each article at the time of publication. Utilization of CIDs allows articles to be fully citable as soon as they are published online, and connects the same identifier to all online and print versions of the publication. SPIE uses a six-digit CID article numbering system structured as follows:

- The first four digits correspond to the SPIE volume number.

- The last two digits indicate publication order within the volume using a Base 36 numbering system employing both numerals and letters. These two-number sets start with $00,01,02,03,04$, $05,06,07,08,09,0 A, 0 B \ldots$ OZ, followed by 10-1Z, 20-2Z, etc. The CID Number appears on each page of the manuscript. 


\title{
Contents
}

\author{
vii $\quad$ Author Index \\ ix Conference Committee \\ xi Introduction
}

\section{OPTICAL FIBER SENSORS AND APPLICATIONS}

967902 Analysis and optimization of all-fiber polarization transformers [9679-3]

967903 A new deformation measurement method for heavy-duty machine tool base by multipoint distributed FBG sensors [9679-4]

967904 Study on spatial resolution improvement of distributed temperature sensor system by linear fitting algorithm [9679-5]

967905 Phase noise measurement of phase modulation microwave photonic links [9679-9]

967906 Research progress of the resonant fiber optic gyroscope technology [9679-10]

967907 Study on the characteristics of different infrared transmission in atmospheric turbulence [9679-13]

967908 Demonstration of $20 \mathrm{~Gb} / \mathrm{s}$ polarization-insensitive wavelength switching system for highspeed free-space optical network [9679-15]

967909 Selected cladding mode recoupling based on cascaded LPG and TFBG for satellites vibration environment monitoring [9679-16]

9679 OA Design and optimization of power current transformer based on FBG sensing [9679-19]

9679 OB Stabilization technique of optic fiber delay lines for photonic sensing [9679-21]

9679 OC A new method for testing the scale-factor performance of fiber optical gyroscope [9679-22]

9679 OD The temperature and tension characteristics of the FBGs embedded in the polythene sheath of an optical cable [9679-23]

9679 OE A high-speed transceiver with optical SerDes [9679-24]

9679 OF Using the combination refraction-reflection solid to design omni-directional light source used in underwater wireless optical communication [9679-25] 
9679 OG Design and realization of a test system for 50Gbit/s optical transmission [9679-26]

$9679 \mathrm{OH} \quad$ Improved artificial bee colony algorithm for wavefront sensor-less system in free space optical communication [9679-27]

9679 Ol Optimization of receiving power distribution using genetic algorithm for visible light communication [9679-28]

9679 0J Filtering and analysis on the random drift of FOG [9679-29]

9679 OK Reducing PAPR of optical OFDM system based on PTS and companding joint algorithm [9679-31]

$9679 \mathrm{OL} \quad$ Hydrogen loading to the optic fibers for fiber grating sensors [9679-33]

$96790 \mathrm{M}$ The effects and inhibition of frequency offset on differential phase-shift keying detection [9679-34]

9679 ON Research of single-polarization hollow-core photonic crystal fiber active resonator [9679-35]

$967900 \quad$ A novel dispersion flattened and single-mode terahertz photonic crystal fiber with materialfilled structure [9679-37]

9679 OP All-optical signal processing technique for secure optical communication [9679-39]

$96790 Q \quad$ Low-flattened dispersion photonic crystal fiber with high birefringence and low effective mode area [9679-40]

9679 OR The research and analysis of the uniformity of the magnetic field of the square Helmholtz coil [9679-42]

9679 OS Phase-sensitive optical time domain reflectometer for distributed fence-perimeter intrusion detection [9679-43]

9679 OT A source number estimation method for single optical fiber sensor [9679-44]

9679 OU Refractive index insensitive curvature sensor based on cladding-mode resonance of specialty triple-clad fiber [9679-45]

9679 OV Optical inclinometer based on a single long-period fiber grating combined with a large lateral offset [9679-47]

9679 OW High temperature sensitivity fiber sensor based on M-Z interferometer fabricated by suspended dual-core hollow fiber [9679-49]

9679 0X Improved optical pulse heterodyne demodulation scheme for fiber-optic interferometric sensors [9679-50]

9679 OY Study on pattern recognition method based on fiber optic perimeter system [9679-51]

$96790 Z$ Field trail of fiber optic ocean bottom cable [9679-55] 
967910 A direction detective asymmetrical twin-core fiber curving sensor [9679-56]

967911 Impact of dither-based Electro-Optic Modulator bias control on distributed Brillouin sensing system [9679-57]

967912 Theoretical investigations of terahertz polarimetric devices [9679-60]

967913 Analysis of the polarization characteristic of a satellite-to-ground laser communication optical system [9679-63]

967914 Effect of the glass transition of coating adhesive on temperature performance of fiber optic gyroscope and its optimization [9679-66]

967915 Investigation of the MQAM modulation schemes in downlink of space optical communication system [9679-68]

967916 Channel estimation for OFDM system in atmospheric optical communication based on compressive sensing [9679-69]

967917 Design and achievement of an efficient low-order pointer multiplexing and mapping scheme [9679-70]

967918 The theory research of multi-user quantum access network with measurement device independent quantum key distribution [9679-71]

967919 Research on polarization noise of hollow-core photonic crystal fiber resonator optic gyroscope [9679-72]

9679 1 A An optical fiber point liquid level sensor [9679-73]

9679 1B Analyze and experiment on AC magnetic field's effect to fiber optic gyroscopes in compact stabilization control systems [9679-75]

9679 1C Tunable and integrated RF photonic phase shifter based on phase modulation and FBG filtering [9679-76]

9679 1D Simultaneous measurement of temperature and strain by using a wide-band fiber Bragg grating [9679-79] 
Proc. of SPIE Vol. $9679967901-6$

Downloaded From: https://www.spiedigitallibrary.org/conference-proceedings-of-spie on 26 Apr 2023 Terms of Use: https://www.spiedigitallibrary.org/terms-of-use 


\title{
Authors
}

Numbers in the index correspond to the last two digits of the six-digit citation identifier (CID) article numbering system used in Proceedings of SPIE. The first four digits reflect the volume number. Base 36 numbering is employed for the last two digits and indicates the order of articles within the volume. Numbers start with 00, 01, 02, 03, 04, 05, 06, 07, 08, 09, OA, OB...0Z, followed by 10-1Z, 20-2Z, etc.

\author{
An, Maowei, OW, 10 \\ An, Yan, 13 \\ Bi, Weihong, OU \\ Chang, Shuai, 07 \\ Chen, Ailin, OK \\ Chen, Guanghui, OD \\ Chen, Yangyi, 17 \\ Chen, Yi-wang, 07 \\ Chen, Yongli, 12 \\ Chen, Zhengyu, 05 \\ Cui, Shu-Min, 18 \\ Deng, Ming, OV \\ Dong, Fengzhong, 04 \\ Doug, Ke-yan, 13 \\ Duan, Jie, OP \\ Duan, Tao, 08, OP \\ Feng, Huan, 08 \\ Feng, Lishuang, ON, 12, 19 \\ Fu, Guangwei, OU \\ Fu, Xinghu, OU \\ Gao, Kan, OD \\ Gao, Xinlu, 1C \\ Gao, Yingjie, 05 \\ Gao, Yi-wei, 02 \\ Ge, Junfeng, $1 \mathrm{~A}$ \\ Geng, Hongjian, 16 \\ Geng, Tao, OW, 10 \\ Gong, Ying, 1A \\ Gu, Wanyi, 1C \\ Guo, Hao, OM \\ Guo, Tuan, 09 \\ Guo, Yun-Zeng, OJ \\ Han, Xiang'e, $\mathrm{OH}$ \\ Hao, Shiqi, 16 \\ Hou, Shiyue, 1C \\ Hu, Junpeng, OT \\ Hu, Xiaoyang, 11 \\ Hua, Bin, $1 \mathrm{~A}$ \\ Huang, Jian-ping, $\mathrm{OB}$ \\ Huang, Shanguo, 1C \\ Huang, Wenzhu, $\mathrm{OZ}$ \\ Huang, Zhiping, OT, 17 \\ Ji, Yi-Ming, 18 \\ Jia, Yangjing, OK \\ Jiang, Lun, 13 \\ Jiao, Hongchen, ON, 19 \\ Jin, Zhonghe, 06 \\ Lai, Haiqiang, OX \\ Lei, Dongming, OK
}

Li, Bowen, 15

\author{
Li, Chao, OC \\ Li, Fang, $\mathrm{OZ}$ \\ Li, Hongpu, 1D \\ Li, Jian, 10 \\ Li, Jianhua, 00 \\ $\mathrm{Li}$, Jing, OC \\ $\mathrm{Li}$, Jinwen, OE \\ Li, Jun, 04 \\ Li, Mi, 15 \\ Li, Min, OY \\ Li, Ping, OK \\ Li, Ruiya, 03 \\ Li, Yun-Xia, 18 \\ Li, Zhijun, 1B \\ Liang, $\mathrm{H}$., $\mathrm{OA}$ \\ Lin, Chen, OD \\ Lin, Shao-feng, OP \\ Liu, Bohan, 14 \\ Liv, Chao, 09 \\ Liu, Chunwu, OT \\ Liu, Feng, OJ \\ Liu, Jun, OR \\ Liu, Mingyao, 03 \\ Liv, Qiang, OU \\ Liu, Shu, OG \\ Liu, Sufang, OS \\ Liu, Weisheng, 09 \\ Liv, Yi, 03 \\ Liu, Yuhan, OI \\ Liu, Yumin, Ol \\ Long, Keping, 0 ol \\ LU, Bin, OS \\ LU, Jun, OR \\ Luo, Yingbo, $O Z$ \\ Luo, Zhang, $\mathrm{OE}$ \\ Ma, Huilian, 06 \\ Ma, Lin, 14 \\ Mao, Yao, 1B \\ Meng, S., OA \\ Meng, Wen, 18 \\ Meng, Zhou, OX, 11 \\ $\mathrm{Niu}, \mathrm{Chaojun}, \mathrm{OH}$ \\ Pan, Ming, OS \\ Pan, Xin, OR \\ Pan, Zhi-yong, OL \\ Pan, Zhongming, OM \\ Pang, Zhengbin, $\mathrm{OE}$ \\ Peng, Yunfeng, $\mathrm{OI}$
}


Qian, Feng-chen, 08, OP

Rao, Jionghui, OF

Ren, Jun-jiang, $\mathrm{OB}$

Ren, N. K., OA

Sha, Jianbo, OD

Shi, Haiyang, OC

Shi, Lei, 18

Shi, Lei-lei, OV

Song, Peng, $0 Q$

Song, Wenshuai, ON, 19

Song, Yuejiang, 15

Su, Bing, OP

Su, Shaojing, OG, OM, OT, 17

Sun, Han, 16

Sun, Miao, 04

Sun, Qiao, 11

Sun, Shilin, 11

Tam, Hwa-yaw, 09

Tan, Yuegang, 03

Tang, Yuquan, 04

Tian, Jing, 1B

Tian, Yun-Peng, OJ

Tu, Guojie, 15

Tu, Xiaobo, OX, 11

Wang, Chao, 13

Wang, Huali, 00

Wang, Jianfei, OX

Wang, Jing-yuan, 07, 00

Wang, Jinpeng, OK

Wang, Junjie, ON

Wang, Kefei, $\mathrm{OE}$

Wang, Linglan, 06

Wang, Ning, 15

Wang, Peng, 1D

Wang, Rong, 07

Wang, Tieshui, 14

Wang, Yueze, 14

Wang, Zhaogang, $\mathrm{OZ}$

Wang, Zhe, 07

Wei, Wen-jie, OB, OL

Wei, Yi-mei, 07

Wei, Yongfeng, 1C

Wen, Linqiang, OF

Wen, Yu, 08

WU, Bingyan, OD

Wu, Chen, OR

Wu, Chuanxin, 00

Wu, Limin, $O Q$

Wu, M. Z., OA

Xian, Lunlun, 1D

Xiao, Chun, OB, OL

Xiao, Yue-yu, 02

Xie, Haiyang, $\mathrm{OU}$

Xiong, Y. L., OA

$X U$, Chaolong, $\mathrm{OE}$

$X \cup$, Cheng-lin, OB

$X U$, Haiyan, $O Y$

$X \cup, Z$ Zhen-Yu, 18

$\mathrm{Xu}, \mathrm{Zhiguo,} 05$

$\mathrm{Xu}$, Zhi-yong, 07, 00
Yan, Yuchao, 06

Yang, Fan, OW

Yang, Hui-xiang, 02

Yang, Shuang, 04

Yang, Wenlei, OW, 10

Yang, Xiao-Jun, OJ

Yao, Wenming, OF

Ye, Lin, $1 \mathrm{~A}$

Ye, Quanyi, 05

Ye, Ya-lin, 08, OP

Yin, Feng-yang, OV

Yu, Haicheng, OC

Yu, Hao, 14

Yu, Xuhui, OS

Zeng, Hongyi, OW, 10

Zhang, Baofu, 00

Zhang, Bingxin, $O C$

Zhang, Chao, 1B

Zhang, Hongjie, $1 \mathrm{~A}$

Zhang, Jun, OD

Zhang, Mingliang, OD

Zhang, Qian, OP

Zhang, Wei, 1A

Zhang, Wentao, $0 Z$

Zhang, Xiao-qiang, OL

Zhang, Xuewu, OY

Zhang, Xuping, 15

Zhang, Ya-lin, 13

Zhang, Yimeng, OT, 17

Zhang, Yingjie, 15

Zhang, Zhuo, OY

Zhao, Ji-yong, 07

Zhao, Ming, OD

Zhao, Qingsong, 16

Zhao, Zhengxin, $0 \mathrm{C}$

Zhou, Deliang, OS

Zhou, Jing, OM

Zhou, Zhen, 12

Zhou, Zude, 03

Zhu, Tao, OV

Zhu, Yuan, OL

Zou, Nianyu, OK

Zuo, Zhen, 17 


\title{
Conference Committee
}

\author{
Conference Chairs
}

Guangjun Zhang, Beihang University (China)

Byoungho Lee, Seoul National University (Korea, Republic of)

\section{Conference Co-Chairs}

Desheng Jiang, Wuhan University of Technology (China)

Hequan Wu, Chinese Academy of Engineering (China)

Huitao Fan, Aviation Key Laboratory of Science and Technology on Infrared Detector (China)

Junhao Chu, Shanghai Institute of Technical Physics, CAS (China)

Jannick Rolland, University of Rochester (United States)

Lin Li, The University of Manchester (United Kingdom)

Lijun Wang, Changchun Institute of Optics, Fine Mechanics and Physics, CAS (China)

Min Gu, Swinburne University of Technology (Australia)

Qiming Wang, Institute of Semiconductors, CAS (China)

Wei Wang, Beijing Institute of Aerospace Control Devices of CASC (China)

Yue Hao, Xidian University (China)

Zheng You, Tsinghua University (China)

\section{Program Committee}

Andreas Tünnermann, Friedrich-Schiller-Universität Jena (Germany) Baiou Guan, Jinan University (China)

Bin Xiangli, Shanghai Engineering Center for Microsatellites (China)

Byoungho Lee, Seoul National University (Korea, Republic of)

Buwen Cheng, Institute of Semiconductors, CAS (China)

Chun Tang, Institute of Applied Electronics, CAEP (China)

Chunhua Shen, The University of Adelaide (Australia)

Chueh Ting, Tianjin Jinhang Institute of Technical Physics (China)

Daniel Jaque, Universidad Autónoma de Madrid (Spain)

Dae Wook Kim, The University of Arizona (United States)

Dawei Zhang, University of Shanghai for Science and Technology (China)

Honghai Liu, University of Portsmouth (United Kingdom)

Haimei Gong, Shanghai Institute of Technical Physics, CAS (China)

Jannick Rolland, University of Rochester (United States)

Jinxue Wang, SPIE

Jin Lu, Tianjin Jinhang Institute of Technical Physics (China)

Jianping Chen, Shanghai Jiaotong University (China)

Junpeng Guo, The University of Alabama in Huntsville (United States) 
Kevin P. Thompson, Synopsys, Inc. (United States)

Lan Jiang, Beijing Institute of Technology (China)

Lin Li, Beijing Institute of Technology (China)

Ligong Zheng, Changchun Institute of Optics, Fine Mechanics and Physics, CAS (China)

Lijun Wang, Changchun Institute of Optics, Fine Mechanics and Physics, CAS (China)

Lin Li, The University of Manchester (United Kingdom)

Min Gu, Swinburne University of Technology (Australia)

Minghui Hong, National University of Singapore (Singapore)

Minlin Zhong, Tsinghua University (China)

Nanjian Wu, Institute of Semiconductors, CAS (China)

Satoshi Kawata, Osaka University (Japan)

Shibin Jiang, AdValue Photonics, Inc. (United States)

Sen Han, University of Shanghai for Science and Technology (China)

Suijian Xue, National Astronomical Observatories, CAS (China)

Tsutomu Shimura, The University of Tokyo (Japan)

Weibiao Chen, Shanghai Institute of Optics and Fine Mechanics, CAS (China)

Wei Wang, Beijing Institute of Aerospace Control Devices of CASC (China)

Weiping Yang, National University of Defense Technology (China)

Xiaocong Yuan, Shenzhen University (China)

Yang Ni, New Imaging Technologies (France)

Yanbiao Liao, Tsinghua University (China)

Yongcai Guo, Chongqing University, Ministry of Education (China)

Yongchun Xie, China Academy of Space Technology (China)

Yong Bi, Academy of Opto-electronics, CAS (China)

Yong Cheng, Wuhan Ordnance Non-Commissioned Officers

Academy (China)

Zhiping Zhou, Peking University (China)

Session Chairs

1 Xuefeng Wang, Beijing Institute of Aerospace Control Devices of CASC (China)

2 Ciming Zhou, Wuhan University of Technology (China)

$3 \quad$ Yi Jiang, Beijing Institute of Technology (China)

$4 \quad$ Yuanhong Yang, Beihang University (China)

5 Hongdu Liu, Hua Tuo Technology (Beijing) Company, Ltd. (China) 


\section{Introduction}

Applied Optics and Photonics, China (AOPC2015) is the annual conference of the Chinese Society for Optical Engineering, and it is also the largest academic and industrial event in the field of optical and optoelectronic technology in China. The AOPC2015 organization committee intended to build a cohesive platform for academic exchanges, industry exhibitions, and corporate negotiations. The conference had 7 themes, which included 22 technical conferences and 600 technical presentations. We sincerely hope that the research and development of optoelectronic technology was promoted, and that the international cooperation of the optical and optoelectronic industry was enhanced.

AOPC2015 was sponsored by the Chinese Society for Optical Engineering; SPIE, the Optical Society, the European Optical Society, and the Optical Society of Korea were technical co-sponsors. There were also 28 cooperating organizations that supported the conference. We received a total of 1,219 contributions from more than 15 countries, including: the United States, the United Kingdom, Germany, France, Spain, Australia, Canada, Mexico, Brazil, Japan, Republic of Korea, Thailand, Singapore, Russian Federation, and China. Nearly 700 submissions were accepted for the Proceedings of SPIE, and over 150 invited talks and papers were suggested to be published in Journals indexed by $\mathrm{SCl}$ and $\mathrm{Ei}$. After careful discussion, we selected five plenary speeches, which were presented by famous scientists from the United States, the United Kingdom, Republic of Korea, Japan, and China. There were 205 invited talks in 12 of the technical conferences. On behalf of the organization committee of AOPC, I express thanks to all of the invited speakers and authors for their contributions to and support of the conference.

To celebrate the International Year of Light 2015, we set up 12 display boards highlighting IYL in the exhibition area on the first level. These display boards were to educate the public about light and the applications of light in society.

Finally, on behalf of Prof. Songlin Zhuang, the other co-chairs, and the organization committee of AOPC, I would like to heartily thank our sponsors and cooperating organizations for all they have done for the conference. I thank all of the participants and friends for their interest and efforts in helping us make the conference a success. I also thank the program committee for their effective work and valuable advice-especially the AOPC2015 secretariat and the SPIE staff for their tireless effort and outstanding services in preparing the conference and publishing the proceedings. 
Again, we extend our warmest greetings to you and hope you had a pleasant and exciting stay in Beijing!

Guofan Jin

Proc. of SPIE Vol. 9679 967901-12

Downloaded From: https://www.spiedigitallibrary.org/conference-proceedings-of-spie on 26 Apr 2023 Terms of Use: https://www.spiedigitallibrary.org/terms-of-use 